\title{
Trajetórias de vida em perspectiva histórica: Joey Ramone e Marky Ramone
}

\author{
Life trajectories in historical perspective: \\ Joey Ramone and Marky Ramone
}

Fernando Mendes Coelho ${ }^{1}$

\begin{abstract}
Resumo: este artigo tem como objetivo discutir alguns elementos que marcaram a geração de jovens norte-americanos dos anos 1960 e do início dos anos 1970, a qual, após o final da Segunda Guerra Mundial, experimentou um período de insatisfação política e social, que levou a inúmeras contestações frente aos comportamentos conservadores estabelecidos até então. Desta forma procuraremos, a partir da análise de alguns trechos de obras autobiográfica e biográfica dos músicos Marky Ramone e Joey Ramone, identificar como os jovens, antes de se tornarem astros do rock mundial, enfrentavam os dilemas políticos e culturais dos Estados Unidos, como a repulsa à Guerra do Vietnã, os atritos com a geração dos seus pais e a negação ao movimento hippie. Discutiremos que o surgimento da contracultura apresentou diversas vertentes e, que em contradição aos que apenas queriam paz e amor, havia nos subúrbios urbanos algo mais agressivo, que veio posteriormente a se estruturar como o movimento punk. Todos esses elementos perpassam as incertezas dos anos de juventude dos nossos personagens, que são o centro do objeto da pesquisa, e com a utilização de análises biográficas como fontes de pesquisa histórica, procuraremos explorar as possibilidades metodológicas deste campo teórico para consolidar a argumentação desta pesquisa.
\end{abstract}

Palavras-chave: Contracultura. Punk rock. Juventude. Estados Unidos.

Abstract: this article aims to discuss some elements that marked the generation of American youth of the 1960 s and early 1970s, which, after the end of World War II, experienced a period of political and social discontent that led to numerous conservative behaviors established so far. In this way, we will analyze the autobiographical and biographical works of musicians Marky Ramone and Joey Ramone in order to identify how young people before becoming world rockers faced the political and cultural dilemmas of the United States, such as the repulsion of war of Vietnam, the friction with the generation of his parents and the denial of the hippie movement. We will discuss that the emergence of the counterculture presented several aspects, and that, in contradiction of those who only wanted peace and love, on the other hand, there was something more aggressive in the urban suburbs, which later came to structure itself as the punk movement. All these elements permeate the uncertainties of the youth of our characters, who are the focus of the research, and that, with the use of biographical analysis as sources of historical research, we will explore the methodological possibilities of this theoretical field to consolidate the argumentation of this search.

Keywords: Counterculture. Punk rock. Youth. United States.

\footnotetext{
1 Graduado em Ciências Econômicas pela Universidade Federal do Paraná, Graduado em História pela UNESPAR, Mestre em História pela Universidade Federal do Paraná e Doutorando no Programa de Pós-Graduação em História da Universidade Federal do Paraná, na linha de pesquisa de Intersubjetividade e Pluralidade, Curitiba, PR, Brasil. ORCID: http://orcid.org/0000-0001-8790-2266. E-mail: fermcoelho@hotmail.com
} 


\section{Hey ho, let's go!}

A segunda metade do século XX foi marcada por intensas mudanças econômicas, culturais e sociais, as quais afetaram todo o mundo, tanto pelo lado ocidental quanto pelo lado oriental. As economias capitalistas centrais, após o crescimento econômico e a opulência do consumo em massa experimentados no pós-guerra, passaram a enfrentar crises culturais e econômicas em seus territórios, principalmente após o final dos anos 1960, com os movimentos estudantis e das minorias que vieram a se espalhar pelo mundo. O começo dos anos 1970 consolidou a crise de identidade das novas gerações frente à distensão do Estado de Bem-Estar Social, potencializada com as crises do petróleo após 1973, que levaram a crescentes incertezas e à contestação das ordens estabelecidas no pós-guerra² .

Nestes tempos complexos, que foram caracterizados pelo surgimento de vários movimentos sociais, sobretudo sustentados pela bandeira da contracultura, percebemos uma movimentação de jovens urbanos de cidades como Nova York e Londres, os quais influenciados por esse momento histórico buscaram formas de enfrentamento através da formação de uma cultura própria, marcada pela música, pela estética e pela ideologia anarquista contrária ao sistema capitalista. Estes grupos formados principalmente por jovens desiludidos pelo futuro das sociedades industriais e pela cultura de massa, se organizaram, em grande parte, nas periferias das grandes cidades. Desse processo, somado à impaciência com os movimentos pacifistas, como o hippie, cristalizou-se uma aura de agressividade e energia, um turbilhão que originou o movimento punk após a segunda metade dos anos $1970^{3}$.

Diante desse cenário, este artigo, tem como objetivo identificar elementos que demonstrem o choque cultural e os descontentamentos que originaram as tensões que resultaram na cisão dos ideais da geração nascida no pós-guerra, que passou a se opor aos valores morais e culturais de seus pais e da sociedade industrial vigente. Desta forma, utilizaremos como fonte a biografia de Joey Ramone, e a autobiografia de Marky Ramone, integrantes da banda de punk rock, internacionalmente reconhecida, chamada Ramones, a qual é considerada uma das bandas mais influentes do período ${ }^{4}$, tendo seu primeiro disco lançado em $1976^{5}$. Porém, o que buscamos quando analisamos a fonte, é abordar alguns trechos das biografias em que os

\footnotetext{
2 "Sob o calçamento, a praia" ou "Tudo, rápido!", proclamavam os muros de Paris em maio de 1968. Antes que aparecesse, logo depois, "No Future", isto é, não mais presente revolucionário. De fato, vieram, nos anos 1970, as desilusões ou o fim de uma ilusão, a desagregação da ideia revolucionária, a crise econômica de 1974, a inexorável escalada do desemprego em massa, o enfraquecimento do Estado de Bem-Estar Social, construído em torno da solidariedade e a partir da ideia de que amanhã será melhor do que hoje, e as respostas, mais ou menos desesperadas ou cínicas, que apostaram todas no presente, e somente nele (HARTOG, 2015, p. 147).

3 Alguém poderia pensar que essa simplicidade é herdada dos hippies, da sua recusa da complexidade das formas modernas de vida em favor de uma harmonia com o "natural", entendido como retorno à essência da vida do Homem. Não é, no entanto, a simplicidade natural que está em jogo aqui; nada na fotografia remete à tranquilidade bucólica das comunidades retiradas, almejadas pelos hippies. Tudo ali diz respeito à cidade e a sua artificialidade e estilo de vida agressivo, desde o cenário (um muro caindo aos pedaços e repleto de pichações, que faz lembrar o estereótipo do subúrbio nos filmes que retratam os espaços marginais das cidades americanas nas décadas de setenta e oitenta, até as roupas e a "caras de mal" (MORAES. 2010, p. 19).

4 What was needed, according to New Wavers, was a radical stripping down the basics. This process had already begun by mid-decade among a group of bands performing in a small New York called CBGB. The Ramones, Television, Talking Heads, Patti Smith, and Blondie developed a style of music that returned to the garage-band ethos of the mid-1960s (MOORE, 2003, p. 177).

5 The quality that insured the Ramones first album would become one of the most important records in modern rock was the same quality that guaranteed the would never have mainstream sucess in their time: a unified vision, the force of a single idea. there is a purity to
} 
personagens escolhidos para análise ainda não eram internacionalmente reconhecidos, ou seja, boa parte do que buscamos explorar são as narrativas na fase “pré-Ramones”. O objetivo, então, recai em perceber como as biografias narram os momentos em que Joey e Marky enfrentavam os dilemas de suas juventudes, os momentos conturbados da Guerra do Vietnã e como eles se posicionavam perante as crises políticas e os choques culturais com a geração anterior.

Na autobiografia de Marky Ramone exploramos para além de alguns traços de sua juventude. Avançamos no caminho que ele trilhou até se tornar um integrante dos Ramones. Entramos no universo da banda para compreender como era o relacionamento de Marky com os outros Ramones, bem como as diferentes formas com que eles viam o mundo no período da Guerra Fria. Já na biografia de Joey Ramone, vamos mais fundo nos medos e incertezas do então Jeffrey Hyman, nome verdadeiro de Joey antes de adotar o seu nome artístico, e de seu irmão, Mickey Leigh, autor da biografia. Buscaremos trabalhar na biografia de Joey, as origens das tensões que marcaram a geração a partir do seu ponto de vista. Claro que, no recorte estabelecido, estamos ocupados apenas nos dois biografados, mas, este esforço pode ser ampliado para os resultados alcançados por essa geração, sobretudo, por que nossos dois personagens foram, e ainda são, mesmo após suas mortes, grandes influenciadores das gerações que aí estão, e das que estão por vir.

\section{Biografias, contando histórias de uma geração}

A utilização do gênero biográfico na produção historiográfica é uma ferramenta tradicional, mas assim como a historiografia passou por mudanças paradigmáticas ao longo do seu desenvolvimento como ciência, a utilização das biografias e autobiografias como fontes históricas também sofrem o impacto dessas mudanças epistemológicas. Desta forma, não cabe neste artigo debater as nuances e ressignificações que o gênero passou ao longo do desenvolvimento da historiografia, no entanto, o esforço teórico pode ser apreciado na obra de François Dosse, chamada O Desafio Biográfico ${ }^{6}$. Nesta obra, o autor analisa, através do tempo, o gênero biográfico, dando destaque ao papel que desempenhou no desenvolvimento não só da História, como também das Ciências Sociais, estabelecendo um debate interessante entre as diversas vertentes e os tipos de biografias que estão presentes na História7.

Este artigo procurará utilizar como método de análise biográfica algumas noções desenvolvidas na obra de François Dosse, o qual coloca ao longo do texto as mudanças que o gênero passou, ganhando importância para a análise histórica:

\footnotetext{
ramones that is almost overwhelming and frightening. Basically, the Ramones are the only punk group from the 1970s to have maintained their vision for so long, without compromise - a vision fully and completely expressed on their very first álbum (ROMBES, 2005, p. 4). 6 Hoje, o que se exprime com essa nova paixão biográfica não é a figura do mesmo, a da História magistrae vitae, do culto da vida exemplar, mas uma nova preocupação pelo estudo da singularidade e uma atenção particular aos fenômenos emergentes que são considerados como objetos próprios para pensar graças à sua complexidade e à impossibilidade de reduzi-los a esquemas mecânicos (DOSSE, 2015, p. 406). 7 A pertinência da entrada no mundo histórico pela biografia é defendida por Wilhelm Dilthey em torno da noção de Erlebnis, ou seja, a possibilidade de "reviver" a experiência histórica. Enquanto a corrente durkheimiana nega qualquer pertinência à biografia, a sociologia, mais compreensiva, faz dela seu objeto privilegiado na medida em que ela integra, ao ato de saber, a implicação subjetiva daquele que sabe (Id., 2015, p. 340).
} 
A biografia, durante muito tempo, se limitou a transcrever o percurso de homens ilustres, deixando de lado o homem comum, tributário das decisões dos poderosos. A crítica desse privilégio concedido aos estratos superiores da sociedade gerou uma historiografia que reorientou seu olhar para as massas e as lógicas coletivas (DOSSE, 2015, p. 297).

Ou seja, as narrativas biográficas, por muito tempo apenas reproduziram os discursos dominantes a partir de exemplos de vida, que sustentavam uma determinada hegemonia social com representações de homens ilustres como modelos para manter uma ordem social. Eram exemplos a serem seguidos pela massa da população sem contestações, limitando muitas vezes o papel da biografia ao reforço de discursos estabelecidos, principalmente exaltando os vultos históricos institucionais, como chefes de Estado ou patronos de instituições, como o Exército, ou de grandes líderes empresariais.

A metodologia histórica para análise biográfica mudou ao longo do desenvolvimento epistemológico da ciência, sobretudo com o surgimento da Nova História Cultural, principalmente após os anos 1980, nos quais os manejos com as fontes ganharam uma nova amplitude e possibilidades teóricas, temos então o que François Dosse chamou de "o retorno do biográfico"8.

Aproveitando o crescimento da Nova História Cultural, e o retorno do biográfico, fazemos uso desse tipo de fonte para perceber como as narrativas de vida de jovens norte-americanos dos anos 1960 expressavam a sua forma de enxergar o mundo. O novo campo da análise histórica do estudo biográfico deixa claro que o relato de vida do homem comum passa a ser válido. Quando buscamos os recortes destes jovens antes de se tornarem astros do rock mundial, é isto que estamos buscando. Joey Ramone e Marky Ramone, em muitas das passagens analisadas, ainda são Jeffrey Hyman e Marc Bell, jovens comuns da cidade de Nova York.

\section{Marky Ramone, além da bateria}

A primeira autobiografia analisada é a do baterista Marky Ramone, com o título de Minha vida como um Ramone - Punk Rock Blitzkrieg. O autor, Marc Bell (futuramente Marky Ramone), nasceu no ano de 1952, um baby boomer ${ }^{9}$, como ele cita na obra, buscando uma identidade a qual seguir na sua juventude:

Eu tinha passado a infância tentando fugir do estilo rigoroso da geração de Segunda Guerra Mundial. Mas na verdade eu também não fazia parte da geração de Woodstock. Eu estava em algum lugar entre as duas. Eu não podia afirmar que tinha um plano na vida. E podia imaginar muitos amigos meus sentindo a mesma coisa (RAMONE, 2016, p. 114).

\footnotetext{
8 Com o "retorno" do biográfico, alguns historiadores não renunciaram ao empenho de chegar até os anônimos da história. De diversas maneiras, mostram que é possível superar as falhas das fontes para descobrir qual tenha sido seu mundo (Id., p. 297).

9 Apesar de haver variações nas datas propostas pelos diferentes autores, pode-se considerar que os Baby Boomers são as pessoas nascidas entre 1948 e 1963; a geração X, pessoas nascidas entre 1964 e 1977; a geração Y aquelas que nasceram entre 1978 e 1994 (ENGELMANN, 2009).
} 
Identificamos nesse trecho, que o autor expressou a sua incerteza sobre quem ele era, e para onde queria seguir, e que, também, era um traço da geração de jovens do seu tempo, principalmente pelo medo do alistamento para a Guerra do Vietnã, e de um possível conflito nuclear entre norte-americanos e soviéticos. Era um bombardeio de acontecimentos e influências, pois foi momento do choque de gerações dos adultos que viveram a Segunda Guerra Mundial e de jovens que surgiam lutando pelos mais diversos direitos, como os hippies, com a bandeira de Paz e Amor, e o movimento negro, lutando por igualdade em uma sociedade americana racista, movimentos que não passaram batidos por Marky Ramone.

Pois bem, a autobiografia inicia-se com uma rica descrição da infância e da juventude do autor, passada no condado do Brooklyn, em um bairro eminentemente composto por proletários. Retrata as suas experiências escolares, receios, problemas de convivência com a vizinhança, e de como era visto como um mau exemplo para os amigos das redondezas, pois as mães dos seus amigos logo proibiam seus filhos de brincarem com o pequeno Marc. Nessa fase surge o interesse do autor por tocar bateria, a qual ficava horas e horas treinando - detalhe também para a influência do rádio, pois quando ganhou do seu pai um radinho portátil, no início dos anos 1960, passou a perceber um mundo novo.

É interessante a forma como o autor descreve os assuntos históricos, a partir de suas lembranças infantis, como o professor de Educação Física, veterano da Guerra da Coréia que exigia dos garotos treinos praticamente militares, com dezenas de flexões ou abdominais, e a forma que a sua professora recebeu a notícia da morte de John Kennedy.

Em 22 de novembro de 1963 eu estava na minha classe da sexta série quando um dos professores entrou na sala e disse que o presidente John F. Kennedy tinha sido assassinado em Dallas, no Texas. Nossa professora começou a chorar e, quando a viram, algumas meninas também caíram no choro. Eu tinha certeza que minha mãe estaria fazendo a mesma coisa (RAMONE, 2016, p. 28).

Percebemos nestes trechos, as ressonâncias de acontecimentos históricos no dia a dia das pessoas comuns que viveram esse momento, e um dos pontos fortes do livro é justamente este: é possível fazer várias relações e entender como se constitui a cultura norte-americana do período, notando quais eram as principais tensões existentes na vida de um jovem do Brooklyn, e como o rock surgiu como forma de expressão dessa geração.

No início da carreira musical, Marc Bell descreve com riqueza de detalhes as pessoas que ele conviveu e os lugares onde tocou com suas primeiras bandas, bem como o primeiro grande contrato com gravadores e álbuns de estúdio. Nesse período passou por importantes bandas, como Dust e Richard Hell and Voidoids, inclusive fazendo as suas primeiras viagens internacionais, como para a Inglaterra. Relata, inclusive. o período de crise econômica existente naquele país e as incertezas nas quais viviam os jovens da época. O rock n'roll servia como forma de extravasar formas de angústia e ansiedade da juventude inglesa da primeira parte da década de 1970. Marky observa que bandas que teve contato na sua viagem para a Inglaterra, como: 
The Clash, os Sex Pistols e o Damned estavam cantando sobre a Inglaterra oprimida, e não estavam mentindo. [...] Muitos milhares de trabalhadores desempregados estavam vivendo do seguro desemprego. Havia pedintes nas ruas. Assaltos e até ataques aleatórios estavam acontecendo todo dia. Havia um desamparo generalizado (RAMONE, 2016, p. 134).

Em 1978, já de volta aos Estados Unidos, é convidado para entrar para os Ramones, que já estavam em atividade desde 1974. Para Marky, que já era um músico experiente, foi a grande oportunidade de entrar para uma banda com o sucesso já consolidado. Os Ramones já eram conhecidos nos Estados Unidos e na Inglaterra como precursores do punk rock. A partir desse momento, temos a parte principal da obra autobiográfica de Marky Ramone, pois ele descreve o seu período de quinze anos como um Ramone, ele ficou na banda até o seu término, no ano de 1996, com um intervalo de 1983 a 1987, que ficou fora da banda por problemas de convivência com seus parceiros por conta do alcoolismo.

Pois bem, Marky descreve as características comportamentais dos seus parceiros de banda: Joey, Johnny e Dee Dee. Com a saída de Dee Dee, em 1989, conta como foi sua convivência com C.J Ramone até o final da banda. De acordo com a descrição de Marky, cada Ramone tinha um temperamento diferente, o que muitas vezes causava conflitos entre os integrantes da banda. Os conflitos já foram destacados em outras biografias de ex-músicos da banda que não fazem parte deste artigo, porém são importantes para entender como se constituíram os Ramones e quais foram seus desdobramentos, como, por exemplo, a biografia de Dee Dee Ramone $^{10}$. Marky, então, procura definir cada um dos seus parceiros de banda desta forma:

Se eu tivesse tempo, ficaria feliz em contar para elas (pessoas que usam camisas dos Ramones, mas não conhecem a banda) quem eram aqueles sujeitos de verdade. A importância das convicções políticas de John foi exagerada. Não importava quão autoritário ele fosse de vez em quando na van, no fim das contas ele amava os Estados Unidos justamente pela liberdade. Dee Dee era um poeta preso no corpo de um punk. Ele nunca encontrou de fato a liberdade que buscava na Terra, mas o passeio que proporcionou ao resto de nós foi libertador. Joey era um punk hippie que encontrou uma liberdade própria e peculiar no porão na loja de arte da mãe, e deu de presente para o mundo (RAMONE, 2016, p. 436).

Marky relaciona nessas definições, como o conceito de liberdade é colocado como adjetivo para cada um dos Ramones, identificando nas características pessoais como as suas próprias representações de liberdade eram expressas, e de que forma se traduziram para o mundo e para o próprio Marky que conviveu muitos anos com eles. A liberdade surge como um valor singular de cada sujeito, cada um desses jovens teve o seu reconhecimento como astro da

10 A ramones story can't really have a happy ending. I'm just glad it's over with, though some of it was fun. I really don't think the Ramones should play together again. I say that not out of meanness; it's actually out of concern for them, and myself. I wish everyone in the band good luck. Because of our relationships with each other, we're all damaged (RAMONE et al., 2000, p. 287-88). 
música internacional justamente em um momento de crise da sociedade capitalista, onde o modelo industrial era o da uniformização e da sociedade em massa. O movimento punk, e o punk rock, brotam da crise industrial como mais um elemento da contracultura, logo, podemos interpretar que a liberdade de cada Ramone surge da possibilidade da heterogeneidade de cada um, rompendo as amarras da sociedade centrada na razão na qual eles nasceram ${ }^{11}$.

Observamos que, por mais que fossem um grupo de músicos que se consolidaram a partir de um nome, existiam diferenças na maneira como viam o mundo, a prova disto é que devido a essas diferenças, alguns problemas de relacionamento inevitavelmente surgiram ao longo do caminho.

É descrita a intensidade da relação entre os membros, no qual o autor enfatiza a antipatia entre Joey e Johnny, que mal se olhavam e não se falaram durante anos, por mais que convivessem nas viagens e nos shows da banda. O baterista coloca Dee Dee como o seu grande amigo, o qual durante os tempos de descanso ou entre um show e outro, perambulava e fazia turismo por vezes nas cidades onde passavam. Uma passagem marcante aconteceu em uma visita a Alemanha, na qual, Marky e Dee Dee visitaram o Muro de Berlim, é relevante a forma com que Marky descreve a experiência:

Depois que escureceu, encontramos um trecho do Muro de Berlim com escadas. Subimos as escadas até o topo do muro. Daquele ponto dava para ver pelo arame farpado o outro lado. Berlim Oriental. A diferença era gritante. Berlim Oriental era sombria. Era um mundo de preto, branco e cinza do outro lado da estrada lá embaixo, a apenas cento e cinquenta metros de onde estávamos. Os prédios eram bem largos, repetitivos, estruturas de caixa, sem cor, que pareciam ter saído do mesmo molde. As coisas mais próximas desses prédios que tínhamos nos Estados Unidos eram as prisões. Até a brisa que vinha do lado oriental do muro era estéril e nefasta. O muro nesse ponto era tão largo que era possível caminhar sobre ele. Mas assim que fizemos isso, um monte de lanternas do outro lado acendeu, praticamente nos cegando. Apertamos um pouco o passo, e as lanternas nos seguiram. Foi horripilante. Quem quer que fossem, podiam nos ver muito melhor do que nós podíamos vê-los. Para nós, eram comunistas sem rosto que existiam em um tipo de inferno bem aqui na Terra. Para eles, nós éramos alvos. Estava na hora de descer do muro (RAMONE, 2016, p. 175).

A descrição da experiência do autor em relação a sua visita ao Muro de Berlim demonstra o choque cultural que separa o mundo naquele período de Guerra Fria, beirando inclusive a noção de maniqueísmo, no qual, o lado comunista representava o sombrio e o nefasto, onde

\footnotetext{
${ }_{11}$ Quanto mais racional, produtiva, técnica e total se torna a administração repressiva da sociedade, tanto mais inimagináveis se tornam os modos e os meios pelos quais os indivíduos administrados poderão romper sua servidão e conquistar sua própria libertação. Sem dúvida, a ideia de impor a Razão a uma sociedade inteira é paradoxal e escandalosa - embora se possa discutir a correção de uma sociedade que ridiculariza essa ideia enquanto transforma sua população em objetos de administração total. Toda libertação dependa da consciência de servidão e o surgimento dessa consciência é sempre impedido pela predominância de necessidades e satisfações que se tornaram, em grande proporção, do próprio indivíduo (MARCUSE, 1973, p. 28).
} 
os prédios residenciais da Alemanha Oriental lembrava os presídios norte-americanos. Os ventos que vinham do outro lado também traziam sensações ruins para o narrador.

Podemos compreender a analogia que Marky faz com a palavra liberdade, e com um dos lemas dos Ramones, ou seja, da banda do "faça você mesmo", de certa forma expressava o jeito norte-americano de ver a vida, pois, principalmente durante a Guerra Fria, os Estados Unidos ostentavam a imagem da terra da liberdade, como ainda assim é hoje, mas naquele momento havia o contraste com as nações comunistas, a qual Marky descreve ${ }^{12}$. Outro ponto interessante é a ideia de nós e eles, ou seja, como os comunistas os viam apenas como alvos, e como eles viam os soldados comunistas como sujeitos sem rosto, vivendo em um tipo de inferno bem aqui na Terra. Podemos estabelecer, neste ponto, algumas correlações com a ideia de "Estabelecidos" e "Outsiders", na obra de Norbert Elias, onde os estabelecidos (lado ocidental) criam toda uma estrutura hegemônica de pensamento e, na medida em que essa mentalidade é inserida na cultura dos países do lado Ocidental, quando defrontados com a outra cultura diferenciada (lado oriental), e colocada como rival ou antagonista, são estabelecidos juízos de valor para o outro sistema social, apontados, a partir da ótica de Elias como Outsiders.

\section{Um olhar sobre as tensões geracionais através de Joey Ramone}

Nesta parte do trabalho iremos recorrer a biografia de Joey Ramone, escrita pelo seu irmão Mickey Leigh, intitulada Eu Dormi Com Joey Ramone, publicada no Brasil no ano de 2013. Se anteriormente tratamos da autobiografia de Marky Ramone, iremos recorrer neste momento ao olhar do irmão mais novo de Joey Ramone para contar um pouco da vida do vocalista dos Ramones quando ainda era Jeffrey Hyman, um jovem norte-americano do Queens, de classe média e descendente de judeus. Jeffrey nasceu em 1951, e assim como Marky Ramone também era um baby boomer e estava inserido no mesmo cenário histórico da pujança norte-americana do pós-guerra chegando nas incertezas que floresceram ao longo dos anos 1960, principalmente com o envio de tropas ao Vietnã após 1965.

Vamos buscar na narrativa de Mickey Leigh o que aproxima esses jovens das tensões que envolviam o período histórico no qual viveram a infância e a adolescência, mesmo antes de Jeffrey se tornar o lendário Joey Ramone, e demonstrar como o contexto histórico influenciou na modulação de sua visão sobre o mundo. $\mathrm{O}$ aspecto interessante de tratar com biografias e autobiografias é que, com relatos das trajetórias de vida de figuras públicas, torna-se possível ao pesquisador aproximá-los à esfera de homens comuns. É possível captar os medos, ansiedades e incertezas que podem ser os mesmos de sujeitos que enfrentam as mesmas situações, mas que vivem no anonimato e nunca terão as suas aflições publicadas e lidas pelo grande público.

\footnotetext{
${ }_{12}[. .$.$] podemos perceber que o punk americano, por exemplo, apesar de ter levantado com mais pujança a bandeira contra a cultura$ musical massiva, aproveitara a cena para atingir os ideais e as utopias americanas (como o sucesso pessoal, o american way of life, a livre iniciativa, a igualdade de direitos e oportunidades, entre outros), em que vários desses ideais deveriam ser materializados pela sociedade de consumo (carro, casa, família, cartão de crédito) e legitimados pela comunicação de massa (televisão, rádio, publicidade), mas que não estavam funcionando (SANTOS, 2015, p. 110).
} 
Nesse contexto, os anos 1960 são emblemáticos em relação ao posicionamento dos jovens sobre os assuntos políticos e sobre a formulação de perspectivas futuras em relação aos Estados Unidos e o mundo, tendo em vista que a cultura jovem estava ganhando espaço de destaque. Com isto, os baby boomers passavam a ter representatividade em uma sociedade americana em que a geração anterior possuía raízes conservadoras, religiosas e belicistas, mas em que, por outro lado, seus herdeiros ainda estavam procurando a sua identidade e as bandeiras pelas quais buscavam lutar:

Nós achávamos mesmo que estávamos às vésperas de uma destruição completa. Também achávamos que a juventude dos Estados Unidos estava em maior número agora e que iriámos tomar conta - através da música! (LEIGH, 2013, p. 47).

Interessante notar que talvez o pano de fundo da Guerra do Vietnã e da Guerra Fria afloravam uma sensação de impotência nos jovens, pois, as decisões a respeito do futuro militar dos Estados Unidos estavam na geração anterior, sobrevivente vitoriosa da Segunda Guerra Mundial, porém, como diz o narrador, por mais que achassem que estavam às vésperas da destruição, a nova geração pretendia tomar conta através da música, e não das armas.

É possível perceber também o choque geracional e a imersão do narrador em um processo de resgate da sua consciência histórica, ou seja, ele faz um exercício de memória, de reflexão e de narração a partir de um conjunto de vivências históricas que definem os seus posicionamentos ideológicos perante os assuntos que fazem parte de seus interesses individuais ou coletivos. Para exemplificar esse ponto, é possível recorrer a um trecho em que Jeffrey Hyman e seu irmão Mickey visitam seu pai, que era separado de sua mãe. Ou seja, para os padrões conservadores norte-americanos dos anos 1960, o fato de um casal ser separado já diz muito em relação aos preconceitos que uma dissolução familiar acarreta nos filhos jovens, mas o que queremos explorar no momento é a diferença na visão geracional sobre a Guerra do Vietnã:

O pai apoiava a guerra. A mãe, não. Quem estava certo e quem estava errado? Sabíamos da guerra. Apenas não queríamos ouvir falar nela pelas fontes do nosso pai. Nós não confiávamos nelas (LEIGH, 2013, p. 47).

Percebemos ao longo da citação, que os jovens identificam dois posicionamentos diferentes a respeito da Guerra do Vietnã, o do pai e da mãe, na qual a mãe de Jeff e Mickey é uma artista plástica de vertente progressista. $\mathrm{O}$ alinhamento ao lado da mãe representa a intenção dos jovens de se desarticular do pensamento nacionalista do período anterior, voltado para as conquistas militares norte-americanas. A negação ao posicionamento do pai, com a afirmação de que não gostariam de ouvir falar nela pelas fontes que ele apresentava, denota a criticidade que os jovens tinham a respeito do papel dos Estados Unidos na Guerra do Vietnã, opondo-se principalmente à mentalidade da geração anterior, principalmente de ex-combatentes. 
É um traço da geração norte-americana nascida após 1950 a aversão à guerra, fazendo surgir por um lado o movimento hippie e de outro o movimento punk ${ }^{13}$. Um pouco depois, já no início dos anos 1970, ambos contestavam a sociedade em que viviam. De um lado, os hippies se expressavam pelas suas roupas coloridas, pela sua música e com uma proposta de sociedade diferente da tradicional. Do outro lado, estava o movimento punk, de característica urbana, agressivo, também contestava a sociedade moderna e propunha a sua destruição e a mudança radical de seus valores através de movimento anárquicos, ambos movimentos originados pela descentralização pós-moderna, mas de características bem diferentes ${ }^{14}$. O movimento utilizava roupas escuras e adereços por todo corpo, definindo uma estética muito diferente do movimento hippie, e igualmente possuía a expressão através da música, na qual a banda Ramones foi uma das precursoras.

Retornando aos diálogos do narrador com o seu pai e com o seu irmão, Mickey narra parte de uma conversa, que terminou com uma discussão:

"Isso é importante e vocês vão assistir", nosso pai disse, dando continuidade ao seu sermão de motel. "Esses soldados estão lá lutando e morrendo pelo nosso país, como nós fizemos quando eu estava servindo".

"A gente ouviu falar que essa guerra é imbecil”, Jeff persistiu, estendendo a mão para trocar de canal. "E a mãe disse que você nunca foi pra França. E isso aí também é outra coisa, cara. Ninguém faz ideia porque estamos indo lá!”. "Ei!", o pai gritou, dando um tapa no braço de Jeff e colocando o dedo na sua cara. "Você vai fazer o que eu mandar! Eu entrei pro quartel e estava pronto pra lutar e você também vai quando chegar sua vez. É melhor ter respeito. Do jeito que vocês dois estão, eu não fico surpreso com o que estou ouvindo. O que aquela mãe de vocês está ensinando? Está criando vocês para serem beatniks! E hipniks! Seja lá qual for o nome! E não me chame de cara! Eu não sou o seu cara! Eu sou seu pai! Não sou um dos seus beatniks”! (LEIGH, 2013, p. 47).

O diálogo apresentado possui vários trechos emblemáticos que demarcam o conflito geracional, e o que mais destoa é justamente o papel do jovem em relação ao futuro do seu país na efervescência de conflitos armados ao redor do mundo com a participação norte-americana. A geração anterior projeta a responsabilidade que eles tiveram na Segunda Guerra Mundial na geração posterior, que deveria continuar a missão de manter os Estados Unidos como a maior potência capitalista mundial, nem que para isso, várias vidas, tanto americanas como de vietnamitas, fossem sacrificadas. Desdobrava-se no medo nuclear e de um conflito envolvendo União Soviética e Estados Unidos, levando, talvez o mundo inteiro à beira do apocalipse de uma Terceira Guerra Mundial. Apesar de toda essa tensão que existia no mundo, a mentalidade que

${ }_{13}[$ [...] o movimento punk se apropriou da retórica das crises que faziam parte do cotidiano dos meios de comunicação de massa ao longo do período - entre o final da década de 1960 e início da década de 1970 - e traduziu-os em termos tangíveis (e visíveis) (SANTOS, 2015, p. 106).

${ }_{14}$ O punk é, portanto, uma clara materialização do sujeito pós-moderno: é híbrido, heterogêneo e, ao mesmo tempo, multirreferenciado e sem referência. Sentenciado a ser eterno rebelde, não encontra uma narrativa que lhe conceda um objetivo (por isso niilista) ou que lhe explique as razões de ser como tal (portanto existencialista). Acaba esvaziando o cenário com a sensação de que parece ter sido em vão enquanto observa sua estética - única materialização de sua ideologia - figurar nas vitrines e passarelas (SANTOS, 2015, p. 113). 
predominava era de que os jovens ainda tinham uma espécie de compromisso de continuar o legado e a coragem dos combatentes anteriores, mesmo que, como se coloca no trecho, existisse uma falsa representação de feitos heroicos que não existiram. A prova disto, é que dentro de um discurso de enaltecimento dos militares que estão na guerra, o pai de Jeff e Mickey diz que ele já fez sua contribuição e que os seus filhos, quando chegasse a hora, também fariam. Mas, quando é interrompido por Jeff, principalmente quanto é confrontado com o fato de que nunca foi para a França, fazendo alusão ao dia D, se revolta contra o seu filho, agredindo-o no braço e colocando a culpa da rebeldia dos dois na mãe deles ${ }^{15}$. Continua fazendo uma crítica às características culturais da nova geração, sobretudo acusando os filhos de serem beatniks, que eram um grupo de artistas e intelectuais marcados pela contestação dos valores sociais tradicionais, que serviam de inspiração para os movimentos de 1968 ao redor do mundo ${ }^{16}$.

A relação com o pai foi se tornando cada vez mais difícil e, de acordo com a narrativa de Mickey Leigh, ela não se sustentou, tornando-se mais um exemplo da eloquente onda revolucionária que marcou os jovens daquela geração, e, sobretudo, o distanciamento que existia entre os jovens e seus pais no que se refere aos posicionamentos políticos e ideológicos:

Por volta de 1971 Jeff e eu começamos a nos rebelar ativamente contra nosso pai. Seus valores conservadores causavam forte repulsa em nós dois e faziam com que nos revoltássemos ainda mais. Ele nos apanhava na frente do nosso prédio em seu Cadillac dourado com uma bandeira dos Estados Unidos na janela. Era o auge da era Nixon e naquela época estávamos mais dispostos a incendiar bandeiras - e Cadillacs (LEIGH, 2013, p. 77).

Com a figura paterna desconstruída por Mickey e Jeff, foi natural que os jovens procurassem em outra figura masculina a referência como ideal a seguir. A negação de ambos aos valores morais e éticos do pai resumia assim no ambiente familiar o que estava acontecendo em larga escala em diversos lares dos Estados Unidos, ou seja, são reflexos dos movimentos contraculturais que ganharam fôlego e tiveram o seu auge em 1968. Dessa forma, os dois jovens procuraram como modelo um professor que era engajado nas causas sociais, sobretudo contrário à Guerra do Vietnã, sendo o oposto do que encontravam em seu pai:

Phil trabalhava como orientador educacional na Benjamin Franklin High School do East Harlem, um dos bairros mais perigosos da cidade naquela época, principalmente para um branco. Em 1970 ele havia participado de uma passeata em

\footnotetext{
15 Uma guerra que repercutia e também era travada no território americano, especialmente nas universidades, onde milhares de estudantes protestavam quase diariamente contra o recrutamento obrigatório para o serviço militar, apoiados por uma opinião pública crescentemente contrária à guerra e revoltada com o número de mortos e feridos americanos. Aos 18 anos, os jovens eram convocados para lutar e morrer no Vietnã. No entanto, eles sequer tinham o direito de votar. Teriam ainda que esperar mais três anos para completar 21 e poder escolher um presidente (ZAPPA, 2018, p. 12-13).

16 O movimento beatnik surgido nos Estados Unidos dos anos 1950, foi marcado por intensa produção literária e abordou não somente novas discussões sobre sociedade, política e cultura estadunidenses, mas também a introspecção no próprio existencialismo dos artistas à época do Pós-Guerra. Com a proposta de gerar uma revolução nos padrões comedidos da burguesia, a literatura beatnik surgiu trazendo intensa expressividade e espontaneidade, e um desejo de quebrar com as tradições da literatura americana da época (ROSA, 2017, p. 11).
} 
protesto contra as condições precárias às quais os alunos do coração do gueto eram submetidos e contra a desigualdade nas escolas dos bairros pobres em geral. Os ânimos se acirraram e o protesto quase virou um tumulto. O incidente conseguiu atrair a atenção da imprensa e no dia seguinte havia um artigo de jornal com uma foto de Phil caminhando ao lado das crianças e dos pais da comunidade. Na nossa visão Phil já era um herói. Jeff e eu íamos a todo tipo de passeatas em Nova York e Washington para protestar contra a Guerra do Vietnã. Nos identificávamos com o Phil em praticamente todos os aspectos (LEIGH, 2013, p. 72).

É perceptível, dessa forma, a influência escolar na formação dos jovens, bem como o engajamento do professor, que motivou a participação de Jeff e Mickey em diversas passeadas. Esses movimentos denotam que a sociedade norte-americana não estava apenas fraturada culturalmente e no aspecto geracional, a pobreza e os guetos nas grandes metrópoles eram uma realidade que estava cada vez mais em evidência e demarcavam a desigualdade social. Em 1970, eclodiram uma série de movimentos, foi o período da luta pacífica de Martin Luther King, enquanto os Panteras Negras defenderam a garantia dos direitos negros através da luta armada, havia também os hippies que viviam em comunidades alternativas. Nos anos que se seguiram, gradativamente o Estado de Bem-estar Social posterior à Segunda Guerra Mundial estava ruindo, tendo em 1973, com a primeira crise internacional do petróleo, a sua principal derrota. Temos, então, não apenas culturalmente, mas dentro do contexto econômico mais uma ruptura desses anos de crise, logo, não apenas a sociedade americana estava sendo contestada, como também países europeus como a Inglaterra e a Alemanha. Temos, então, uma fragmentação da modernidade, entrando em um período chamado por um novo movimento teórico, como pós-moderno, no qual os Ramones estavam inseridos, entre a modernidade e a pós-modernidade, como apontado por Nicholas Rombes ${ }^{17}$.

Avançando um pouco no recorte temporal, passamos da adolescência de Jeff, em que procuramos demonstrar os sinais da ruptura geracional dele e de seu irmão, principalmente com seu pai, para a sua vida adulta, já como um astro da música internacional, e agora conhecido como Joey Ramone, para perceber como ele via este mundo envolvido pela crise econômica.

No trecho em que analisamos na autobiografia de Marc Bell, também buscamos algum recorte que demonstrasse como os músicos em suas viagens internacionais percebiam as tensões provocadas tanto pela crise econômica, como pela crise cultural. O ponto em questão é como o movimento punk, iniciado musicalmente pelos Ramones nos Estados Unidos, assumia uma postura própria em outros locais, como, por exemplo, na Inglaterra, na qual bandas como Sex Pistols e The Clash ganhavam notoriedade. Na biografia de Joey Ramone é igualmente possível perceber o impacto que a cena londrina causou nos visitantes no ano de 1976, com o cenário de crise e pobreza, o que deu ebulição aos movimentos contestadores da sociedade moderna, principalmente ao movimento punk:

${ }_{17}$ Ramones is either the last great modern, or the first great postmodern one. Fully aware of its status as pop culture, it noetheless has unironic aspitarions toward arts (ROMBES, 2005, p. 3). 
Ao retornar para Londres percebemos que os punks ingleses tinham a sua própria cena andando a todo vapor. Tinham ainda mais alfinetes de fralda - da língua até as Tetas -, mais moicanos, calças de sadomasoquismo, maquiagem e principalmente mais raiva. Tinham uma causa e motivo para fúria: a pobreza. Era como se agora eles sentissem que haviam ultrapassado o que acontecia em Nova Iorque e que estavam muito além de qualquer coisa ocorrendo nos Estados Unidos (LEIGH, 2013, p. 152).

Esse último trecho, já retirado de um momento referente à segunda metade dos anos 1970, demonstra um extravasamento dos movimentos dos anos 1960, ou seja, em conjunto com a crise cultural, agora a crise econômica atingia a sua fase mais aguda em âmbito mundial. Valores anteriores, inclusive em países mais tradicionais como a Inglaterra, eram contestados, como foi o caso do sucesso "God Save the Queen”, da banda britânica Sex Pistols, que fazia uma crítica à monarquia e à rainha Elizabeth II. Joey Ramone percebia que as tensões que vivia quando jovem referentes ao papel dos Estados Unidos no mundo possuía desdobramentos em diversos países, existia um transbordamento da insatisfação da geração e isto poderia ser observado em diversos países. Ou seja, os movimentos culturais oriundos da crise do capitalismo não se referiam apenas a uma nação, mas sim contemplavam toda a lógica de dominação anterior que estava em crise.

\section{Considerações finais}

Aparentemente, esses jovens comuns e contestadores foram as vozes e os corpos que movimentaram mudanças culturais sem precedentes na história ocidental, e, talvez, o marco principal desse movimento de múltiplas vozes e singularidades tenha sido maio de 1968 em escala global. Temos, nesse emaranhado, diversas histórias de vida, visões diferentes que representaram uma geração que mudou a forma com que a sociedade capitalista olhava para o mundo, porém, ao longo do tempo, por mais que houvesse a contestação, ela acabou sendo absorvida pela cultura dominante. Herbert Marcuse, na sua obra clássica O Homem Unidimensional, define esses diversos movimentos que marcaram a contracultura, e que balançaram as ordens estabelecidas, permitindo mais espaço à pluralidade, navegando além da unidimensionalidade do homem da Razão: o homem “pluridimensional” ou pós-moderno surgia a partir, muitas vezes, das figuras transgressoras, mas que a partir de uma crítica colocada pelo autor, acabava sendo absorvido pelo status quo, e passava a fazer parte da lógica dominante:

A mulher vampiresca, o herói nacional, o beatnik, a dona de casa neurótica, o gangster, o astro, o magnata carismático, desempenham uma função muito diferente e até contrária à de seus predecessores culturais. Não mais imagens de outro estilo de vida, mas aberrações ou tipos da mesma vida, servindo mais como afirmação do que como negação da ordem estabelecida (MARCUSE, 1973, p. 71).

É neste universo que percebemos que Joey e Marky estão inseridos, a crítica de Marcuse, nos serve para pensar que os jovens contestadores dos anos 1960, ao atingirem fama inter- 
nacional, passaram a ser figuras pop, vendendo discos e camisetas em larga escala. Logo, a contestação e a busca de uma sociedade libertária, esbarra na formação de uma cultura que passou a ser inserida na lógica do consumo, transformando o movimento contestador em um mercado para jovens que se identificam com a música e com o visual do punk rock.

Ao longo do que observamos na análise dos trechos das biografias, principalmente na de Marky Ramone, ainda percebemos que apesar de Joey e Marky se afastarem culturalmente da geração pós-guerra, ainda reproduzem valores dominantes norte-americanos. Podemos pontuar isto, quando já na sua maturidade, Marky ainda vê os comunistas de Berlim Oriental de forma sombria e preconceituosa. Como se quem estivesse do outro lado do muro não fosse humano, reforçando que, apesar de ser de uma geração que contestou os valores estabelecidos nos anos 1960 e 1970, ainda reproduzia uma forma ocidentalizada de ver o mundo, basicamente a partir do olhar hegemônico norte-americano.

Por fim, este artigo procurou identificar alguns traços dessa geração que ganhou projeção no final dos anos 1960, e longe da visão romântica, podemos perceber que, apesar da ebulição cultural contestadora, o que temos, ao menos em nossas duas personalidades biografadas, é uma crítica social ao modelo norte-americano, mas, não se contesta a dominação ou as desigualdades sociais, apenas os posicionamentos políticos referentes a assuntos internos dos Estados Unidos. O esforço da análise biográfica se tornou válido porque pudemos operacionalizar, pelo menos do ponto de vista historiográfico, a aplicação da metodologia para identificar a partir dos textos, os pontos nos quais os biografados expressavam os seus descontentamentos e anseios perante uma sociedade na qual eles não se viam inseridos. Dessa forma, Joey e Marky podem ser percebidos como dois jovens que não se enquadravam no pensamento conservador e bélico do pós-guerra, e nem como hippies, estavam criando algo novo, uma forma agressiva de contestar os valores estabelecidos, porém, ao longo do tempo e ao alcançar a fama, reforçaram o american way of life ao enquadrarem os Ramones como baluarte da cena pop mundial ao sair do underground.

\section{Referências}

BERAS, Cesar; FEIL, Gabriel Sausen (org.). Sociologia do Rock. Jundiaí: Paco Editorial, 2015. BELL, Marc. Punk Rock Blitzkrieg: Minha Vida como um Ramone. Trad. Aline Azuma. São Paulo: Editora Planeta, 2015.

DOSSE, François. O Desafio Biográfico: Escrever uma Vida. Trad. Gilson César Cardoso de Souza. São Paulo: Editora da Universidade de São Paulo, 2015.

ELIAS, Norbert; SCOTSON, John L. Os Estabelecidos e os Outsiders: sociologia das relações de poder a partir de uma pequena comunidade. Trad. Vera Ribeiro. Rio de Janeiro: Jorge Zahar, 2000.

ENGELMANN, Deise Cristina. O Futuro da Gestão de Pessoas: como lidaremos com a geração Y? 2009. Disponível em: http://www.rh.com.br/Portal/Mudanca/Artigo/4696/o-futuro-dagestao-de-pessoas-como-lidaremos-com-a-geracao-y.html Acesso em: 31 jan.19. 
GALLO, Ivone Cecília D’ávila. Punk: Cultura e Arte. Revista Varia História, Belo Horizonte, v. 24, n. 40, p.747-770, jul./dez. 2008. https://doi.org/10.1590/S0104-87752008000200024

HARTOG, François. Regimes de Historicidade: Presentismo e Experiências do Tempo. Belo Horizonte: Autêntica Editora, 2015.

KOFMAN, Veronica; RAMONE, Dee Dee. Lobotomy: Surviving the Ramones. New York, Thunder Mouth Press, 2000.

LEIGH, Mickey. Eu Dormi com Joey Ramone: Memórias de uma Família Punk Rock. Porto Alegre: Dublinense, 2013.

MARCUSE, Herbert. A Ideologia da Sociedade Industrial: O Homem Unidimensional. 4. ed. Trad. Giasoni Rebuá. Rio de Janeiro: Zahar Editores, 1973.

MORAES, Everton de Oliveira. Deslocados, Desnecessários: O Ódio e a Ética nos Fanzines Punks (Curitiba, 1990-2000). Mestrado (Dissertação em História) - UFSC, Florianópolis, 2010.

MOORE, Allan F. Analyzing Popular Music. United Kingdom: Cambridge University Press, 2003. https://doi.org/10.1017/CBO9780511482014

ROSA, Alice Câmara. O Livro Beat: O Design de Livros-Objeto de Autores Beatnik. Graduação (Monografia) - Universidade de Federal do Rio Grande do Norte, Natal, 2017.

ROMBES, Nicholas. Ramones 33 1/3. New York/London: Continuum, 2011.

SANTOS, Fernando Silva. There is no Future: Autonomia e Histerologia em Três Acordes. In: BERAS, Cesar; FEIL, Gabriel Sausen (org.). Sociologia do Rock. Jundiaí: Paco Editorial, 2015.

SOTO, Ernesto; ZAPPA, Regina. 1968: Eles só Queriam Mudar o Mundo. 2. ed. Rio de Janeiro: Zahar, 2018.

Recebido em: 5/1/2019.

Aprovado em: 29/3/2019.

\section{Fernando Mendes Coelho}

Doutorando em História - UFPR

fermcoelho@hotmail.com

ORCID: http://orcid.org/0000-0001-8790-2266

Instituição: Universidade Federal do Paraná - UFPR

Endereço Postal: Rua XV de Novembro, 1299 - Centro, Curitiba - PR.

CEP: 80060-000 